\title{
Unha revisión da traxectoria poética de Carlos Negro á luz do seu poemario Estrita necesidade
}

A review of Carlos Negro's poetic career in light of his poetry book Estrita necesidade

\author{
Baldo Ramos ${ }^{1, a}$ \\ ${ }^{1}$ IES de Sar - Xunta de Galicia, España \\ a baldoramos@edu.xunta.es
}

Recibido: 14/10/2021; Aceptado: 07/11/2021

\section{Resumo}

Estrita necesidade é un libro de poesía que retrata os costumes e a ideoloxía da xeración que sofre os últimos anos do franquismo e ve como se suceden os cambios sociais dun xeito vertixinoso. Un libro de familia que indaga sobre as relacións paternofiliais e sobre os pousos que deixa a memoria na ollada do neno que fala nestes versos. Analízase neste traballo o último poemario de Carlos Negro, tendo en conta a súa evolución poética e poñéndoo en relación con outros libros seus que teñen á familia como elemento vertebrador da súa cosmovisión poética.

Palavras-chave: Estrita necesidade; Carlos Negro; poesía galega actual.

\begin{abstract}
Estrita necesidade is a poetry book that portrays the customs and ideology of the generation that suffered the final years of the Franco regime and saw social changes take place at breakneck speed. A family book that delves into the relationships between fathers and children and into the traces left by memory on the gaze of the child speaking these lines. This paper analyzes the latest collection of poems by Carlos Negro, considering his evolution as a poet and relating it to other books by the same author that place the family at the core of his poetic world view.
\end{abstract}

Keywords: Estrita necesidade; Carlos Negro; Galician current poetry.

Hai poetas que dinamitan a realidade cando escriben e hai poetas que a acatan e son respectuosos con ela, aínda que por veces a poñan do revés como quen a cachea para sacarlle todo o que leva nos petos.

Os primeiros son poetas que se ven obrigados a edificar unha realidade alternativa que sexa crible, e iso non sempre resulta doado, o que explica que moitos fracasen no intento, que se frustren no empeño de facer coherente un proxecto poético realmente alternativo ou que simplemente non sexan conscientes do seu fracaso. 
Cando un poeta acepta a realidade como materia literaria sen manipulala excesivamente, sen deixar de facer pé nela para evitar as distraccións do lector ou para non esixirlle máis do debido, tamén corre o risco de ser previsible e superficial ou de non ser valorado pola crítica e os lectores máis esixentes. Estamos diante do dilema de ter lectores escollidos ou lectores masivos.

Pero se xulgamos con imparcialidade o resultado literario, sen deixarnos levar por preferencias persoais nin filias extraliterarias, concluiremos que ser un bo poeta non vai de bandos nin de detonadores, senón de talento e de oficio, esas dúas ferramentas coas que o poeta convencido comunica sen imposturas, sen artes de fogueo.

Carlos Negro non anda con dinamita nos petos cando escribe. 0 seu carácter e a súa ollada fano un poeta observador, paciente, respectuoso co que reclama a súa atención. "Un poeta de microcosmos" ${ }^{1}$, como el mesmo se ten definido.

Os poetas que contan a realidade, que a desentrañan sen destripala, acostuman ter un talante cómplice, comprensivo, conciliador, aínda que o fagan dende a crítica ou a indignación, como o ten demostrado o noso autor en libros como Cultivos transxénicos (2008), Penúltimas tendencias (2014) ou Masculino singular (2016).

Con todo, nestas obras que poderiamos etiquetar como poesía de intervención ${ }^{2}$, empregando a terminoloxía de Miro Villar, Carlos Negro usa a ironía, o paradoxo, a parodia, o sentido do humor e mesmo o sarcasmo para elaborar unha crítica ou denuncia pouco amable, nada cómplice, o que fai destes libros obras realmente novidosas na poesía contemporánea galega. Non tanto polo tratamento poético, que xa tiñan explorado autores como Antón Reixa ou o colectivo Ronselz nos anos 80, como polo enfoque que calibra en varias destas obras dende a perspectiva dos adolescentes, é dicir, dende o punto de vista de quen descobre o mundo dos adultos que perpetúan estereotipos sociais, prexuízos ou costumes discriminatorios dende unha postura incrédula, cómplice ou condenatoria. Este punto de vista poético non se tiña explorado de maneira eficaz nin ambiciosa na poesía galega ata que o noso autor entende que o público adolescente tamén le poesía cando a poesía fala dos seus problemas, das súas inquedanzas ou das súas eivas. Makinaria (2009) e Aplicación instantánea (2018) serían os outros dous libros que podemos situar neste proxecto de intervención social dirixido á mocidade, aínda que o destinatario non sexa exclusivamente este, xunto cos xa citados Penúltimas tendencias e Masculino singular.

Este tipo de escritores, que desentrañan a realidade sen destripala, sempre ten a elegancia de contar a unha distancia prudencial. Porque o bo observador acostuma gardar certa distancia para poder contar con perspectiva e con verdade. Verdade por sincera, por motivada, pero tamén verdade por empatizar co outro, con aquilo do que escribe.

Carlos Negro sabe que para achegar a poesía á xente nova convén ser explícito. Deixar no poema unha mensaxe clara e facilmente codificable. E esta maneira de escribir non é tan doada como ás veces se insinúa desde certos sectores da poesía contemporánea máis hermética.

Pero teño para min que Carlos Negro, como poeta, de cando en vez ten a necesidade de escribir doutro xeito: suxerindo máis que afirmando, insinuando máis que aseverando. Necesidade que sente como creador, pero tamén como poeta dun tempo que non quere desvincularse das poéticas que actualmente gozan de maior recoñecemento na poesía galega. Non así en poesías veciñas como a castelá, na que o cotián, as vivencias persoais e o nesgo social alimentan moitas das voces que hoxe teñen mellor acollida nesa literatura.

E desde esas coordenadas é desde onde se concibiron libros como Héleris (2003) ou Estrita necesidade (2021). 
Poesía na que o autor fala para si, e non tanto para os demais. Arqueoloxía interior na que o traballo consiste en ir levantando capas, en ir reencontrándose coa súa orixe, co que os seus foron nun tempo agora recuperado, reconstruído poeticamente.

Poesía do íntimo, das raiceiras familiares, dos espazos habitados, do tempo compartido, da aprendizaxe dos afectos, do descubrimento dun eu que fai pé no nóse que se fai eco do sentir da tribo.

Trátase dunha poesía que reclama a complicidade do destinatario, que lle esixe máis compromiso e participación na lectura; un xeito de escribir que resulta moito máis enriquecedor para quen le por unha razón sinxela: cando lemos deste xeito vémonos obrigados a desandar os accesos do poema para dar co lugar onde este nace.

A poesía realista avanza sempre cara a diante e o lector só ten que deixarse levar pola semántica que impón o autor; pero a poesía abstracta avanza cara a atrás, e o lector debe rozar a maleza que oculta as mensaxes secretas do poema, esa urdidura de tecidos múltiples que obrigan a reler e convidan a retornar aos textos, xa que a interpretación da mensaxe non é unívoca, non está imposta pola vontade autorial de compartir con nós unha mensaxe explícita, cousa que si perseguía nalgúns dos libros antes citados, nos que transmite valores ou fai reflexionar sobre o machismo, a identidade de xénero, os estereotipos sociais, os cultivos transxénicos...

Neste tipo de poesía o poeta imponse ao poema. 0 poema di exactamente o que el quere, condicionando a súa interpretación e limitando ou restrinxindo a súa descodificación.

Pero en libros como Estrita necesidade, o poema di moito máis do que quere o seu autor. Porque nel deixa ocos para que nós enliñemos co fío da nosa experiencia de vida e da nosa experiencia lectora, cedendo, dalgún xeito, parcelas de coautoría.

Curiosamente as tres obras nas que Carlos Negro experimenta neste sentido son poemarios que teñen á familia como columna vertebral do discurso poético. A familia como espazo biográfico, pero tamén como espazo sociolóxico. 0 íntimo e o público nestes libros conxúganse nas persoas do verbo eu e nós. Por iso o lector se sente recoñecido no relato poético que o autor trama nestas obras, chegando a converterse, dalgún xeito, nun relato de xeración.

Con todo, aínda que sexa paradoxal, estes títulos non van ser os seus libros máis vendidos. E coido que neste dilema se debate o traballo literario do poeta lalinense, que adoita editar os seus libros para público adolescente na Editorial Xerais e o que poderiamos chamar libros de experimentación, nos que ensaia tonalidades máis contemporáneas para a súa voz, acostuma testalos en premios literarios (como acontece con Héleris, Premio Johan Carballeira; con Tundra, Premio Fiz Vergara Vilariño e con Cultivos transxénicos, Premio Victoriano Taibo) ou ben dándollos a publicar a editoras independentes (sería o caso do seu orixinalísimo Abelcebú, en Positivas, ou o seu primeiro libro, As laranxas de alí babá, editado no seu día pola desaparecida Letras de Cal) ou que apostan pola poesía de autor, como acontece co seu último libro, Estrita necesidade, publicado por Alvarellos Editora.

Este dilema no que o autor se debate, e que ao meu xeito de ver enriquece por contraste a súa dobre vertente creativa como poeta, daría para facer unha reflexión sobre os intereses que moven o lector en xeral a mercar libros de poesía e sobre se a poesía que se le nos centros de ensino galegos é unha poesía que afianza lectores e normaliza o xénero, devolvéndolle a dimensión popular que ao longo dos séculos sempre tivo. Pero isto daría para outro traballo.

Paréceme moi clarificador o autorretrato poético que Carlos Negro fai nun poema publicado na prensa en $2005^{3}$ e no que se segue a identificar en 2011 , cando o recupera, en tradución ao 
castelán, como "Autopoética" para unha antoloxía de poesía galega contemporánea publicada por Teresa Seara ese ano en Caracas:

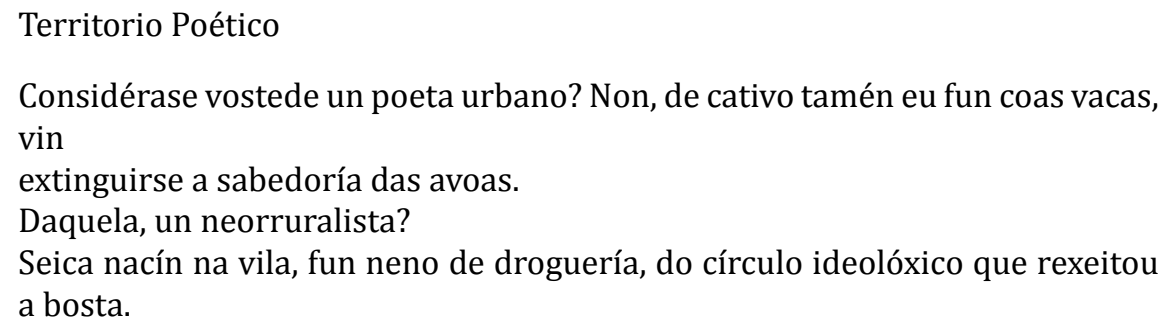

Ao meu entender, nesta autopoética están presentes todos os espazos poéticos que ten percorrido o autor e aparecen perfectamente definidas as súas estratexias e obxectivos literarios, mesmo á esta altura do ano 2021. Vexámolo.

O poeta como suxeito desdobrado, que pon distancia entre realidade e ficción (pero que tamén sabe non ser el ou ser un outro que se lle parece), exprésase aquí mediante o recurso á entrevista, na que vai deixando dun xeito sutil e transparente as claves do seu discurso poético, que poderiamos sintetizar nestas tres características:

- Poesía de raíz rural, pero que fala do mundo das vilas, eses microespazos urbanos tan característicos da demografía galega. 0 tránsito do mundo rural das avoas ao mundo semiurbano da xeración dos pais é o territorio poético que percorre Carlos Negro en libros como Héleris ou Estrita necesidade.

- Poesía de experimentación, aínda que afirme con retranca que non pertence "á constelación das estrelas", quizais porque é consciente de que a súa poética non ten primado esa exploración, aínda que o talante vangardista estea presente en libros como Far-west, Tundra, Abelcebú ou en proxectos de colaboración con outros artistas e escritores como Estrita necesidade ou Tres poetas en estado de alarma. Ademais destes títulos, Carlos Negro ten explorado as posibilidades da poesía visual nalgunha obra que a día de hoxe permanece inédita. 
Deste talante de indagación e da idea apuntada na entrevista con Lupe Gómez de que cada libro é un microcosmos que o autor concibe como unha indagación no territorio poético que condiciona e enriquece a súa linguaxe literaria, coido que é do que nos fala cando afirma que o seu obxectivo como escritor é "Seguirme buscando na polifonía das linguaxes".

- Poesía da experiencia, entendida como poesía que fala de realidades sociais contemporáneas e que integra episodios da vida persoal de forma explícita nos seus textos. Neste territorio poético é no que o autor seguramente teña dado maiores froitos, en libros que teñen acadado reedicións importantes, como Makinaria, Penúltimas tendencias ou Masculino singular. E os seus xa citados Héleris e Estritanecesidade integran eses episodios biográficos do autor e da súa familia que fan que sexan obras que dalgún xeito beben destas tres características que, ao meu entender, definen o seu traballo poético.

En Héleris rastréxanse as orixes familiares do autor, reconstruíndo poeticamente as biografías persoais dos seus pais, simbolizados nos personaxes mitolóxicos de Helena e Paris. Da súa unión nace este libro e o fillo que o escribe. Son os tempos da posguerra, na que a represión, a miseria, o medo, a falta de liberdade, a relixión como ferramenta de control social e cultural facían que a cidadanía non aspirase a vivir fóra dos convencionalismos impostos pola ideoloxía franquista. Unha Galicia gris na que as familias loitan por sacar adiante os seus fillos e mellorar as súas condicións económicas. Pouco máis.

En palabras da crítica Teresa Seara (2011, pp. 131-132):

Estructurado a modo de diario vital de los personajes -desde que nacen hasta que se casan y envejecen juntosHéleris es un canto a la libertad y un amargo recordatorio de lo que fueron los años cuarenta y cincuenta en España.

A estrutura deste libro é simétrica, como máis adiante explicaremos a respecto da súa obra irmá, Estrita necesidade, que tamén respecta unha ordenación dos textos moi meditada.

En Héleris, os primeiros 25 poemas falan por boca da nai e os 25 restantes por boca do pai. Cada bloque describe os seus mundos persoais e reconstrúe simbolicamente as súas biografías.

De tal maneira que os 25 poemas da segunda parte do libro, na que o fillo vai cicelando o retrato do pai nesa longa noite de pedra, teñen moito que ver cos de Estrita necesidade, se ben agora a perspectiva é máis cómplice, máis comprensiva, seguramente pola idade desde a que escribe o autor e por ter vivido a experiencia de ser pai. Con todo, neses 25 poemas dedicados á figura paterna xa aparecen as claves simbólicas que o describen como un personaxe caracterizado polo traballo duro de camioneiro, as longas ausencias do fogar, a súa afección á caza, a escaseza nuns tempos de carestía, a falta de liberdade predicada desde os púlpitos das igrexas, o vínculo coas tradicións rurais... Claves todas elas que definen o pai pero que funcionan simbolicamente como características dun arquetipo social que nos anos da Transición era moi recoñecible: home entregado ao traballo, case por completo desvinculado dos asuntos domésticos, con certos ademáns machistas, respectuoso coas convencións sociais e relixiosas, tradicional e frecuentemente de ideas conservadoras.

Estrita necesidade enfoca a masculinidade dende a perspectiva dunha xeración -a do baby boomque se viu obrigada a estañar unhas fendas e salvar unhas lagoas de comunicación enormes coa xeración anterior, debido a esa abrupta e rapidísima evolución social que o franquismo aprazou nos anos 30 e que impediu durante máis de 30 anos. 
Neste sentido, seguramente este sexa o primeiro libro na poesía galega que pon o foco de forma explícita nesa realidade que lle tocou vivir a unha xeración que, cando mira atrás, nin mitifica o lugar de onde vén nin acaba de romper con el.

E faise nel unha reconstrución cómplice e distante ao mesmo tempo dun xeito de ser pai nos anos nos que o ditador decide deixar o poder, claudicando da vida e do goberno que Deus lle concedera pola graza de roubarnos tres décadas de liberdade. Cómplice e distante. Respectuosa e crítica.

A relación entre pai e fillo está percorrida, por un lado, pola conciencia de clan, de pertenza a unha estirpe (a cita de Olga Novo que abre o libro subliña este tensor do discurso poético: "As túas maos papá as túas maos anciás / de ouro e de fariña"); e, por outro lado, pola conciencia crítica de que ese modelo está superado e de que aceptalo supón unha ruptura (a outra cita que abre o libro, esta de Ismael Ramos, subliña o outro tensor: "O poema é o poema dos pais. / A ferida é a ferida dos pais. / A ferida dos homes. / As cicatrices tamén. / As cicatrices son un dos froitos da ferida. / Os fillos somos cicatrices").

Entre o mundo rural mítico, de fidelidade absoluta a unha raíz, que representa a poética de Olga Novo, e o mundo urbano de superación de estereotipos sociais cos que se rompe dun xeito desenfadado e irreversible, que representa Ismael Ramos, está o territorio permeable das vilas, da clase media que sabe o que costa chegar aí. Unha clase media que rompeu co rural pero tampouco se fixo "urbanita". Porque o rural segue estando próximo para eles, accesible, pero a unha distancia prudencial. Volver á aldea para saber que segue aí, pero non para quedar.

E nese territorio o fillo ten que tomar partido. Acepta, respecta, pero non comparte. Dese dilema aliméntase este libro. E aínda que nestes versos se poña distancia con esa realidade, no fondo hai unha complicidade silenciosa, xenética e poética.

0 pai séntese incomprendido porque o fillo vai cambiar os motores polos libros, a escopeta pola pluma, as rutas de camioneiro pola viaxe poética. E o fillo tamén se sente incomprendido, porque no fondo sabe que romper coa tradición é un xeito de traizoalo.

0 pai quere o mellor para o fillo, dándolle estudos que el non tivo. Confía en que dese xeito prosperará, será mellor ca el, pero non distinto. En ningún caso concibe que os estudos lle poden abrir outros horizontes e o poden afastar irremediablemente do feudo familiar e dun xeito pequenoburgués de entender a vida.

Isto na actualidade xa non pasa tanto, pero a xeración dos que foron pais nos 70 tiña unha teima: que seguiramos os seus pasos, pero para chegar máis lonxe. Non contemplaban a posibilidade de que cambiaramos de camiño.

Dese sentimento de culpa e dese rebelarse sereno beben os poemas deste libro, delatando unha especie de traizón mutua que habilita uns espazos de paradoxo, de renuncia, de silencio, nos que Carlos Negro indaga para facer unha radiografía desa relación entre un pai e un fillo que comparten, si, pero que non pensan igual; que se relacionan, si, pero que non interactúan.

Poesía que é ponte entre o pasado (familiar) e o presente (persoal): oficio de carpinteiro e de escritor, de cazador e de poeta.

Esta obra é unha ponte entre pai e fillo construída coa pedra da fidelidade e coa argamasa do paso do tempo. Un tempo circular que tamén fai pensar ao fillo se, como pai, terá que pasar polo mesmo.

Interpreto no sintagma "estrita necesidade", que estrita fai referencia á austeridade pero tamén á disciplina; e que necesidade fai referencia á carencia pero tamén ao desexo.

Un libro de afectos, pero tamén de desafectos. Un libro de complicidades, pero tamén de incomprensións. Un libro cheo de vida e de memoria, porque a vida e a memoria son iso: fidelidade e contradición. 
Na outra cita que abre o libro xa se confesa, por boca de Pilar Adón, tamén escritora desta xeración nacida no 71, esa distancia prudencial co pai: "Sea yo como mi padre, aunque no del todo".

Carlos Negro sempre concibe e planifica os seus libros de forma minuciosa. E Estrita necesidade non é unha excepción, como imos demostrar.

$\mathrm{Na}$ obra hai un equilibrio perfecto entre eses dous tensores (a fidelidade e a ruptura), que fai do libro unha tirolina de emocións aparentemente contraditorias que consegue darlle profundidade e verosimilitude aos poemas. E conséguese tamén facendo que eses poemas sexan narrativos e poéticos a un tempo. Microrrelatos en verso perfectamente organizados e distribuídos de maneira minuciosa, case matemática, como demostra o feito de que 9 das 10 partes nas que se estrutura o libro estean formadas por 7 poemas ( 7 das 9 partes, curiosamente) e 7 fotografías ( 2 das 9 partes), feito que non semella casual.

A última parte do libro ("cóxegas") é a única que non respecta esta estrutura de 7 unidades agrupadas en fotografías ou poemas, xa que texto e fotografía mestúranse por única vez na obra, funcionando como coda ou epílogo que abre as mans que simbolizan as chaves de paso para acceder á comprensión da vellez (se miramos cara atrás) e á nosa propia experiencia da vellez (se miramos cara adiante).

Unhas mans que atravesan todo o libro, xa que tamén se abre cunha única fotografía que serve de pórtico visual (aparece mesmo antes da portadiña, subliñando xa de inicio a importancia do traballo manual nos episodios biográficos reconstruídos poeticamente polo autor e o papel destacado que ten a achega fotográfica que asina, como coautor do poemario, Benxamín Otero).

Nesa primeira imaxe podemos ver a man do pai en repouso, caída sobre o corpo, iluminada coa luz dos anos da experiencia e dos esforzos de toda unha vida (Figura 1).

Figura 1. Fotografía que serve de pórtico ao libro

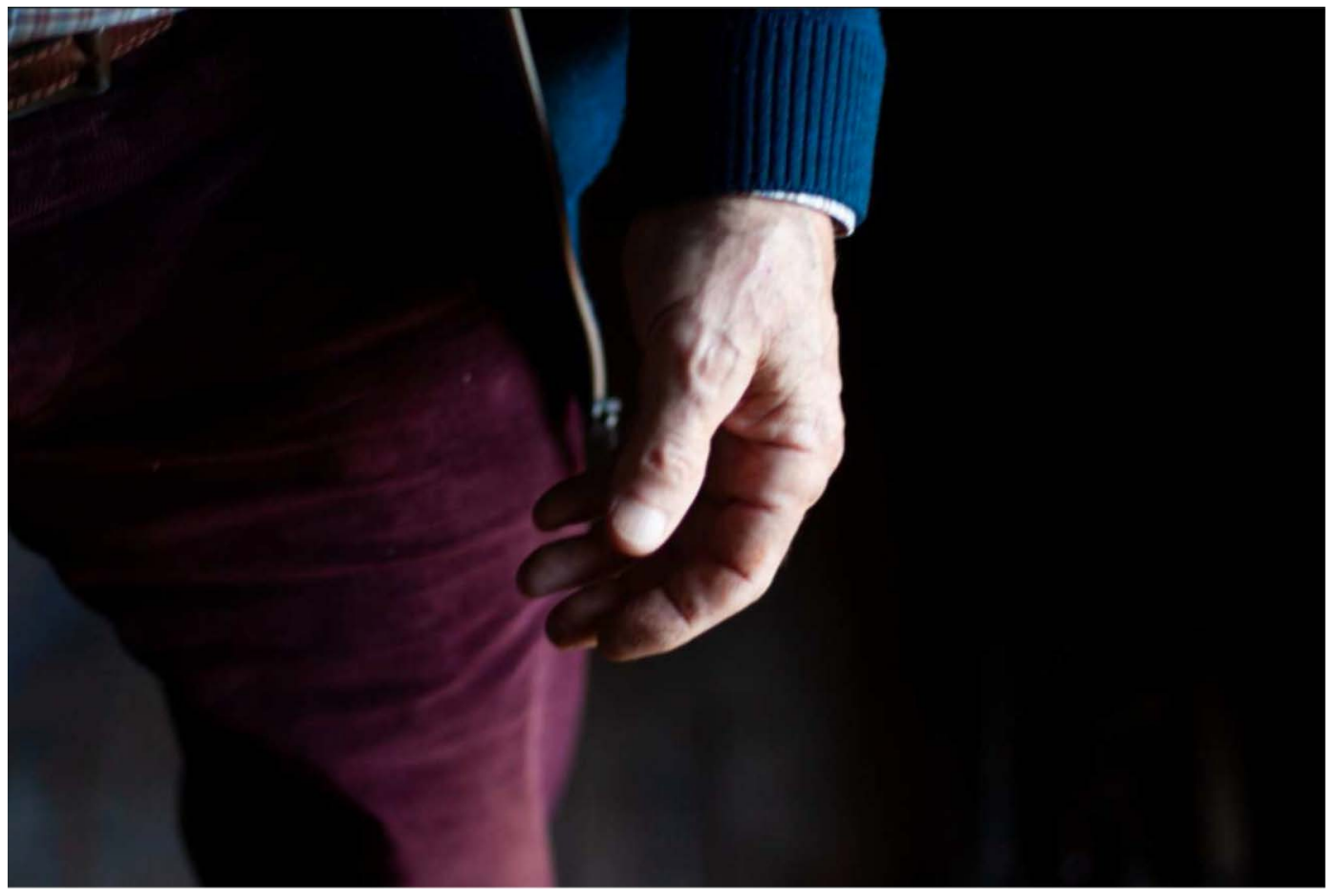

Na primeira parte, "ter conta”, aparecen as mans do pai en 7 fotografías a cor (Figura 2), que evocan un tempo pasado a través das súas engurras e das ferramentas coas que se gañou a vida 
de mozo. Son o relato dun reencontro coas palabras do fillo, que contan dun xeito respectuoso pero tamén crítico e funcionan como instantáneas dun pasado revivido, o que seguramente reforza a pertinencia do discurso fotográfico paralelo que establece Benxamín Otero coas palabras que enfocan eses recordos.

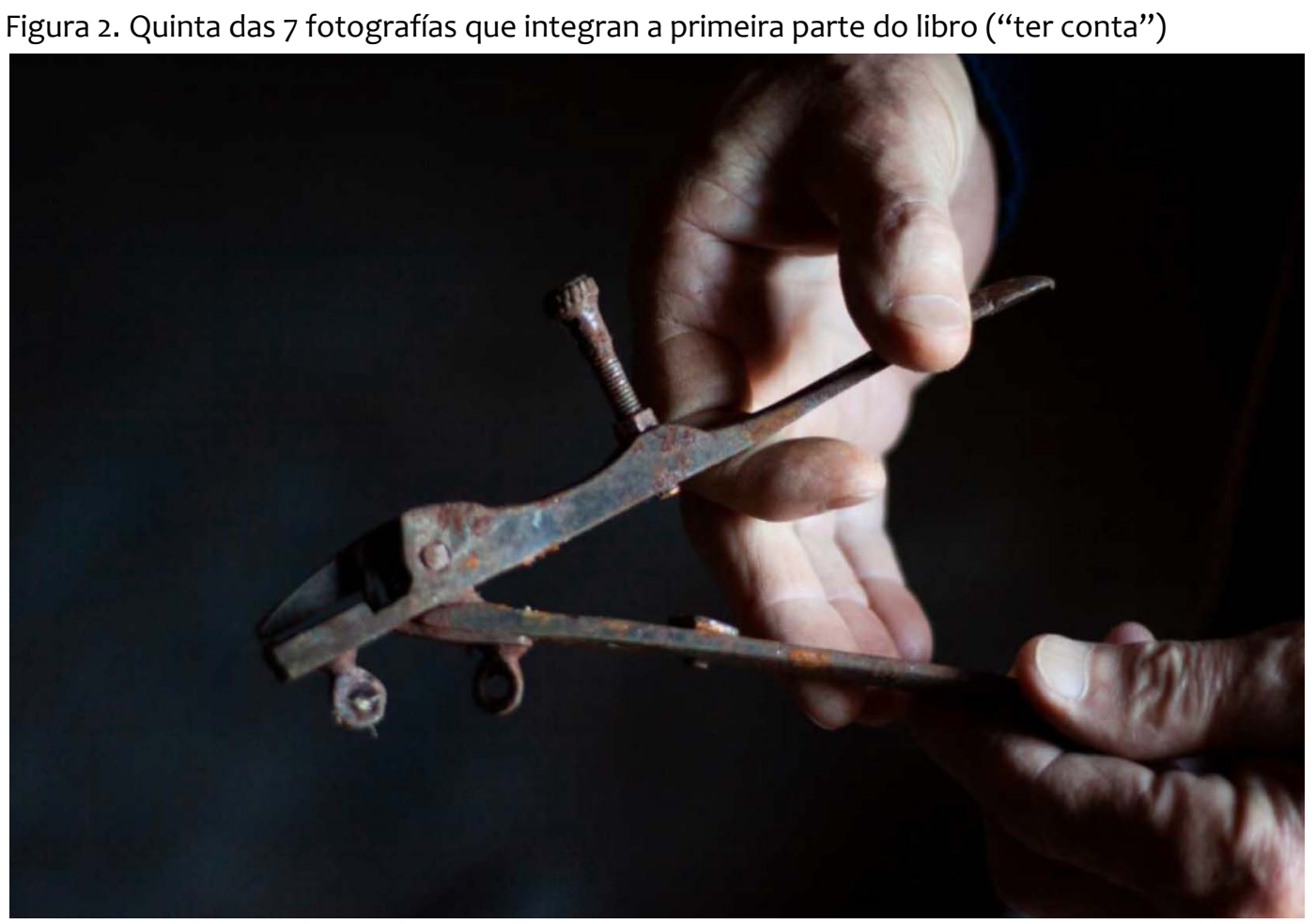

Nunha proporción moi importante de poemas, as mans, o traballo manual, o tacto van enfiando a súa secuencia narrativa. E como na poesía de Carlos Negro nada é casual, o libro péchase con dous pequenos textos que acariñan as mans cunha aliteración de fariña e amor: "as cóxegas na palma da mau polo farelo que cae do bico da peneira / ter conta delas" e "chaves de paso as maus", así como cunha derradeira fotografía en cor (Figura 3) da mesma serie que as que integraban a primeira parte do libro. 


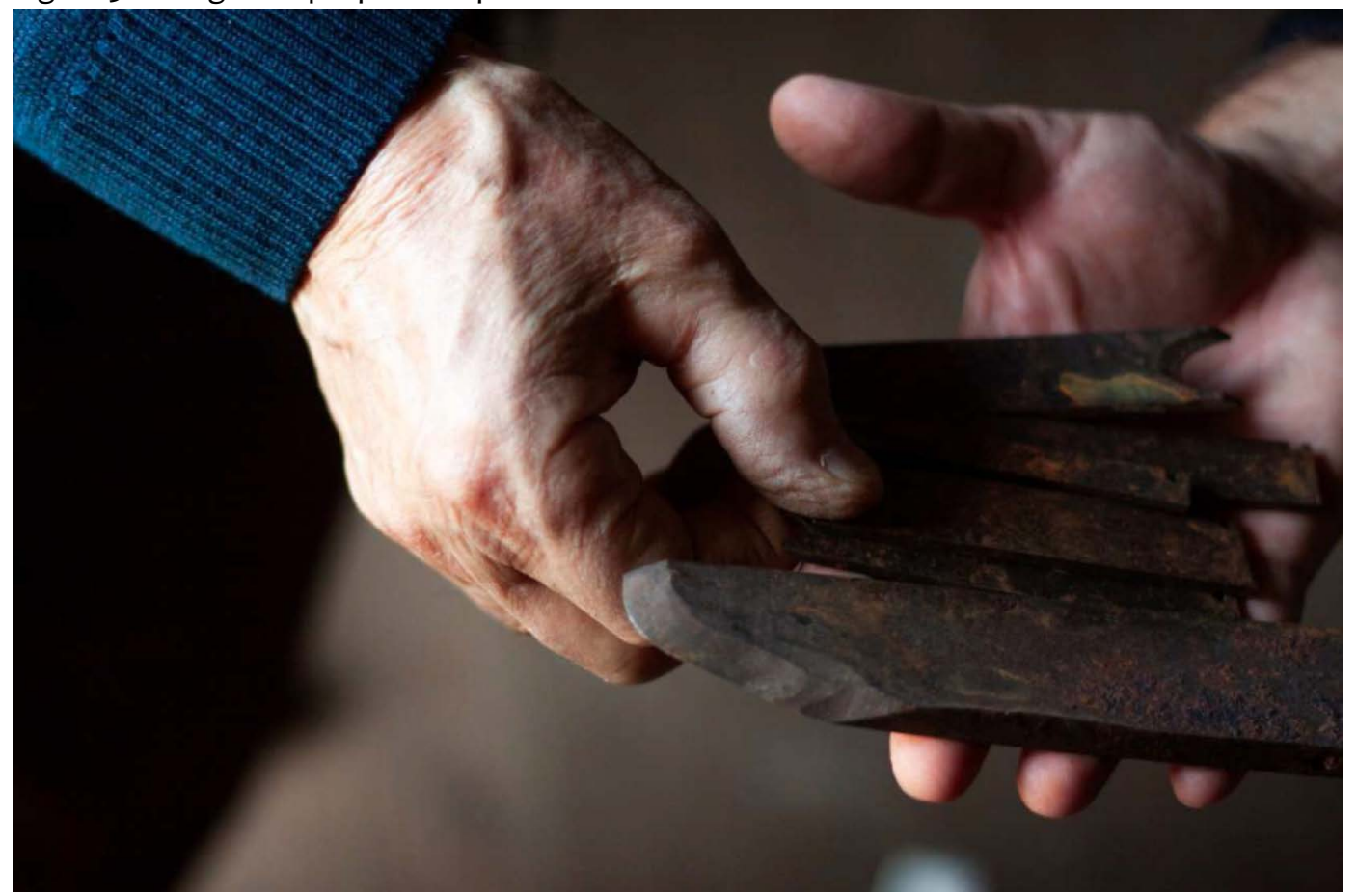

Ter conta delas porque hai que termar do que atesouran, pero tamén porque hai que contar o que nos din. E nesa lectura das mans, o traballo de Benxamín Otero crea unha luz narrativa que conta en paralelo, que nos abre a porta a un pasado e a unha conciencia de pertenza a un lugar e a un tempo. A prana no prato é o resultado dunha habelencia manual que se dignifica neste libro. Unha habelencia que resulta inimitable no oficio de escritor: "ningún verso a esa altura". 


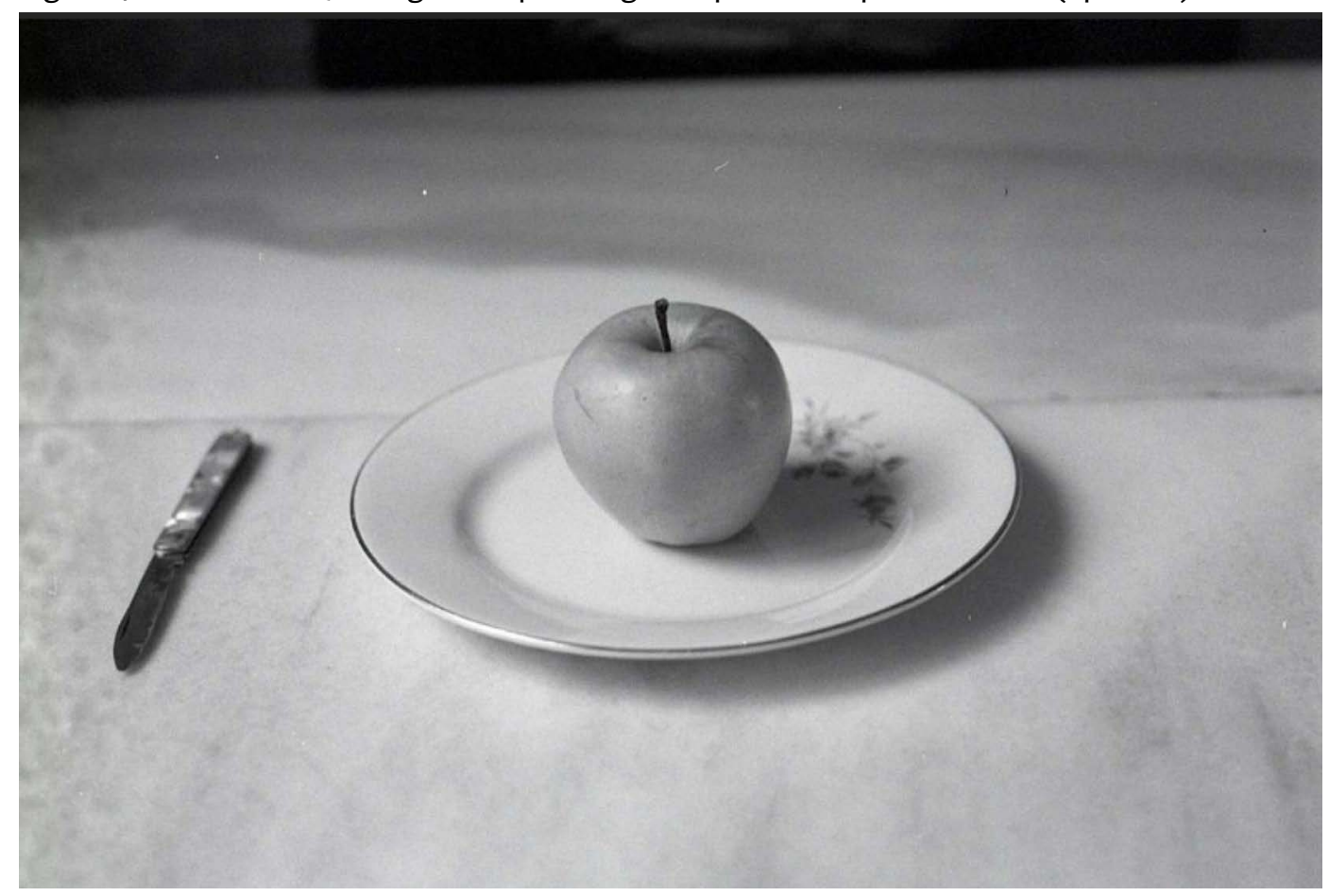

\section{Figura 5. Cuarta das 7 fotografías que integran a penúltima parte do libro ("prana”)}

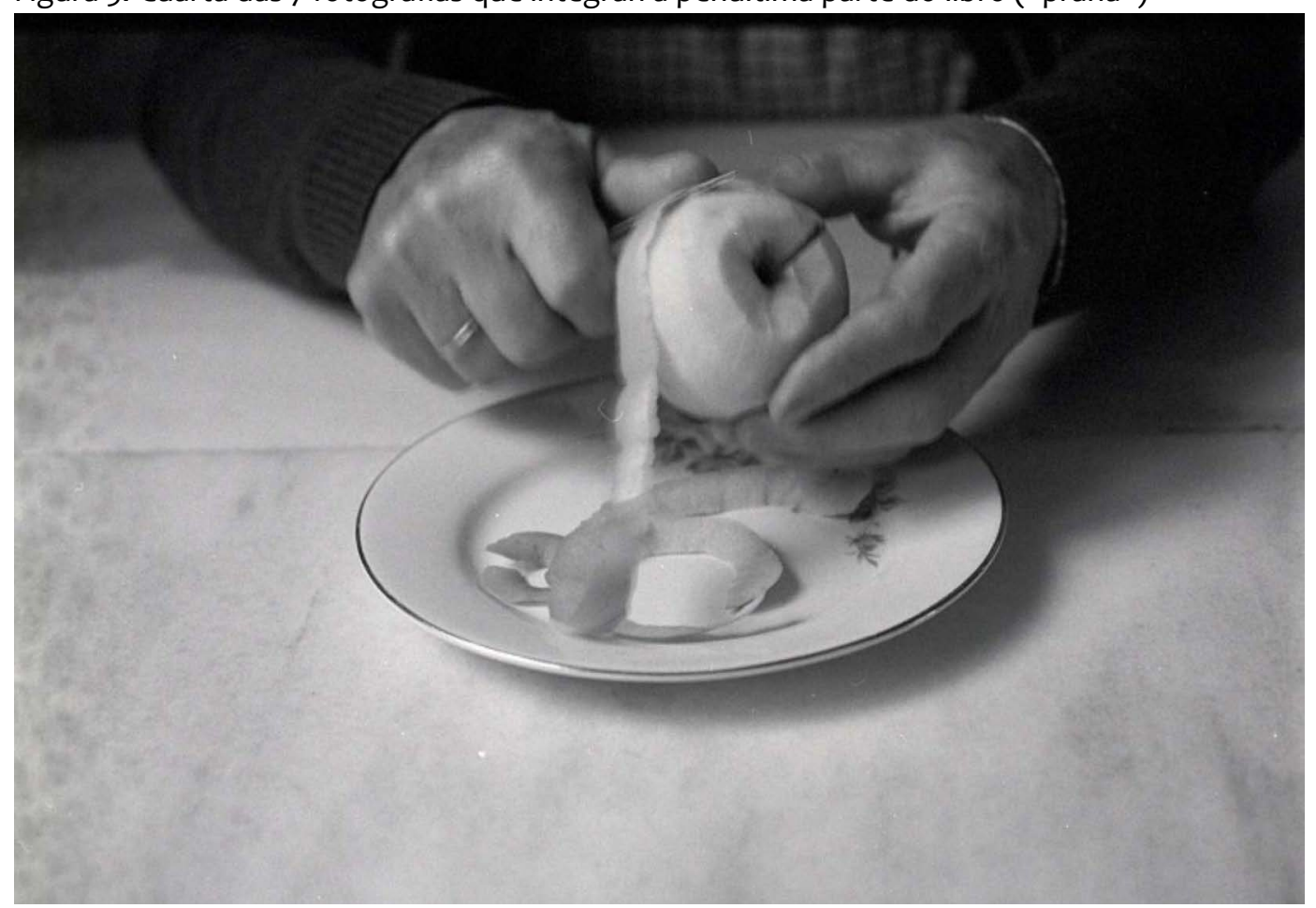

Pero, en realidade, tamén aquí se produce un diálogo co pai por contraste, porque os versos do fillo si que están á altura da incisión finísima que o seu pai consegue na mazá. Precisión que herdou 
seguramente del, pero para pelar o poema ata deixar á vista a polpa zumarenta que reclama o noso apetito lector.

Se contabilizamos todos os poemas do libro darémonos conta de que suman 51 textos (mais o verso final, exento, que semella quedar en suspenso como a fotografía inicial que servía de pórtico ao libro), exactamente os anos que ten Carlos Negro (Lalín, 1970) no momento no que se publica Estrita necesidade.

E van aparecer organizados, tanto os poemas como as fotografías, en conxuntos de 7, como cuncas de caldos simetricamente ordenadas: "sobrevivir era un irse apañando / facer do caldo máis de sete cuncas".

Ademais da ordenación minuciosa, de incisión finísima, Carlos Negro tamén usa como técnica para subdividir a obra a escolla léxica mínima, empregando unha única palabra para titular cada parte, a excepción da primeira, na que escolle a solución oracional "ter conta" cun dobre sentido: como no poema final, para termar, pero tamén porque ter é importante e conta para ese pai que prosperou na vida facendo que aos fillos non lles faltara de nada.

As outras parte do libro titúlanse "caldo" (palabra clave tanto na obra como no noso país, xa que o caldo é o sustento da Galicia dos anos de necesidade, da estrita necesidade); "mula" (porque cumpría traballar coma mulas para sacar unha familia adiante, honradamente, como bestas sacrificadas e sempre dispostas a seguir carrexando); "resina" (o cheiro do amor nesa memoria olfactiva do neno que xa intúe que o monte é unha segunda casa: "un corpo leñoso / o recendo dos corpos a resina”); "cartucho" (o prohibido para ese neno que non entende a morte gratuíta da bubela); "ferramenta" (pesada como lixeiro era o verso que puíu o adolescente coa garlopa de levar a contraria); "granito" (ese romper coa arquitectura tradicional para facer máis evidente a prosperidade); "ferruxe" (porque o tempo iguala toda condición: a ferramenta, a mazá o poema e porque todo envellece e enferruxa); "prana" (nas fotografías cortadas coa precisión minuciosa e cómplice do artista multicisciplinar Benxamín Otero, sen quen este libro non sería o retrato sereno e honesto deste pai sereno e honesto), $e$ "cóxegas" (o epílogo que serve de chiscadela ao avó que mira o futuro e sente que as maus son as portas que abren todas as casas).

Tamén as da poesía. 
Figura 6. Última das 7 fotografías que integran a penúltima parte do libro ("prana”)

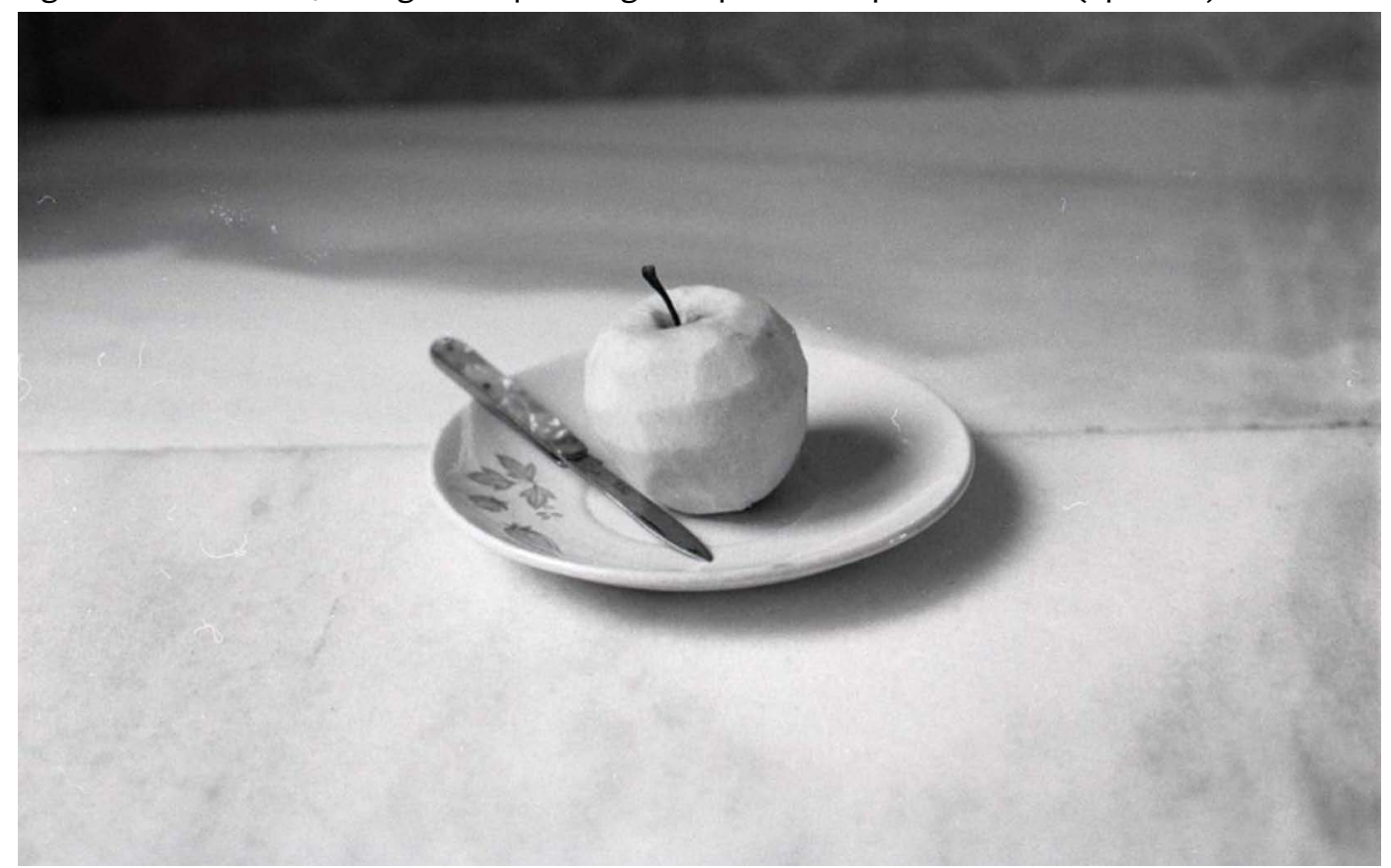

Teño para min que Carlos Negro vai seguir explorando nos vindeiros anos novos territorios, novos microcosmos poéticos, desde unha palabra sempre comprometida co seu tempo e coas súas raiceiras. Deses dous mananciais bebe a súa obra: da fidelidade á súa orixe e da solidariedade coas causas xustas que reclaman a súa atención como poeta de denuncia, comprometido socialmente. Non debemos esquecer a vocación docente do noso autor. E ese estar en contacto sempre coa rúa, coa sociedade, coa escola fai que a súa obra fale de cada un de nós con palabras nas que nos recoñecemos, con palabras que son nosas e que el ordena co maxisterio que lle dá ser un dos poetas de voz máis recoñecible e celebrada da poesía galega das dúas últimas décadas.

\section{Referencias bibliográficas}

Aneiros, R. (11 de novembro de 2004). Agardando as lagarteiras. http://culturagalega.gal/colaboracion_de talle.php?id=3\&aid=212\&autor=rosa.

Dávila, B. (26 de abril de 2014). A poesía, penúltima arma. El Correo Gallego, 42.

Gómez, L. (11 de decembro de 2008). Crónica de entremesturas. Galicia Hoxe, 43.

Lourido, I. (28 de marzo de 2009). Crítica (poética) da Razón Espoliada. Xornal de Galicia, Nós, 16, 5.

Negro, C. (1998). As laranxas de alí babá. Letras de Cal.

Negro, C. (2001). Far-west. Xerais.

Negro, C. (2003). Héleris. Espiral Maior.

Negro, C. (2008). Cultivos transxénicos. Instituto de Estudos Miñoranos.

Negro, C. (2009). Makinaria. Xerais.

Negro, C. (2010). Abelcebú. Positivas.

Negro, C. (2014). Penúltimas tendencias. Xerais.

Negro, C. (2016). Masculino singular. Xerais. 
Negro, C. (2017). Tundra.Espiral Maior.

Negro, C. (2018). Aplicación instantánea. Xerais.

Negro, C. (9 de xaneiro de 2005). Territorio poético. El Correo Gallego.

Negro, C. e Otero, B. (2021). Estrita necesidade. Alvarellos Editora.

Negro, C., Álvarez Cáccamo X. Mà. e Vaqueiro, V. (2020). Tres poetas en estado de alarma. Laiovento.

Nogueira, Ma . X. (2016). Saídas de emerxencias. Tempos novos, 228, 85.

Nogueira, Ma . X. (22-28 xaneiro 2009). 0 derradeiro marco da memoria. A Nosa Terra, 1343, 32.

Penelas Devesa, P. (2014). Poesía xuvenil sen complexos. Grial. Revista galega de cultura, 202, 116-117.

Raña, R. (9 de xuño de 2016). Metamorfose e declaración. Faro de Vigo, Faro da Cultura, 587, VI.

Santórum, G. (2018). Afástase Carlos. Luzes, 52, 89.

Seara, T. (2011). Veinte puntos de fuga. Fundación Editorial El perro y la rana.

Soto, I. (29 de xuño de 2009). Born to run. http://culturagalega.gal/lg3/extra_recension.php?Cod_extrs=2 091\&Cod_prsa=\&Cod_prdccn $=1711$

Villar, M. (2016). Unha refutación do machismo e a súa linguaxe dominante. Grial. Revista Galega de Cultura, 210, 93-94.

Villar, M. (2018). A poética do frío. Grial. Revista Galega de Cultura, 127, 83-84.

Notas

$1 \quad$ Nunha entrevista de Lupe Gómez a raíz da publicación de Cultivos transxénicos, Carlos Negro defínese deste xeito porque, segundo a poeta de Fisteus, “cada libro seu é unha aventura distinta".

2 Miro Villar aplícalle esta etiqueta na súa recensión sobre Tundra (2009).

3 Este poema non se incluíu en ningún dos seus libros e foi publicado por primeira vez en El Correo Gallego (9 de xaneiro de 2005).

Citar: Ramos, B. (2021). Unha revisión da traxectoria poética de Carlos Negro á luz do seu poemario Estrita necesidade. Boletín Galego de Literatura, 59, “Notas”, 1-13. D0I http://dx.doi.org/10.15304/bgl.59.8 $\underline{005}$ 